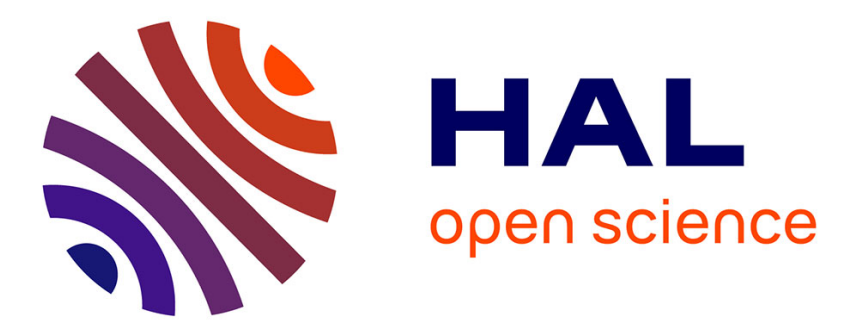

\title{
Un-nudgeable nudgers: An experiment on voluntary contribution to an academic network working on the CAP. A Note
}

Marianne Lefebvre, Jesus Barreiro-Hurlé, Jens Rommel

\section{- To cite this version:}

Marianne Lefebvre, Jesus Barreiro-Hurlé, Jens Rommel. Un-nudgeable nudgers: An experiment on voluntary contribution to an academic network working on the CAP. A Note. Journal of Agricultural Economics, 2021, 10.1111/1477-9552.12418 . hal-03051845

\section{HAL Id: hal-03051845 \\ https://univ-angers.hal.science/hal-03051845}

Submitted on 10 Dec 2020

HAL is a multi-disciplinary open access archive for the deposit and dissemination of scientific research documents, whether they are published or not. The documents may come from teaching and research institutions in France or abroad, or from public or private research centers.
L'archive ouverte pluridisciplinaire HAL, est destinée au dépôt et à la diffusion de documents scientifiques de niveau recherche, publiés ou non, émanant des établissements d'enseignement et de recherche français ou étrangers, des laboratoires publics ou privés. 


\title{
Un-nudgeable nudgers: An experiment on voluntary contribution to an academic network working on the CAP. A Note
}

\author{
Marianne Lefebvre, Jesus Barreiro-Hurlé and Jens Rommel
}

[Original submitted August 2020, Revision received November 2020, Accepted December 2020]

Journal of Agricultural Economics, Volume 72.2, June 2021

\begin{abstract}
Peer networks can positively affect individual careers and the scientific enterprise as a whole. People's willingness to contribute to such networks is poorly understood. In an email experiment, we investigated how framing the future research environment affects people's willingness to contribute to an emerging academic network. In spite of relatively large treatment effects, we do not find statistically significant effects of pessimistic or optimistic messaging on the willingness to contribute. We discuss limitations of the small sample size and the future research potential of network nudges.
\end{abstract}

Keywords: Behavioural economics; Nudging; Willingness to cooperate; research networks; peer communications

JEL Classifications: D71, D85, O31, Q01, Q16

\section{Introduction}

Creating a network of supportive peers is an important aspect of achieving a successful academic career (Ansmann et al. 2004). Engaging in or organizing a network are time-consuming, especially when participation in a network requires working with others for an agreed mission. Career concerns may lead researchers to behave egoistically, especially in the initial phase of networks, when outcomes are still highly uncertain, and anticipated net benefits to an individual may be low or even negative.

Research funding institutions have recognized the value of providing researchers with incentives to engage in networking through dedicated funding such as the EU COST action and various national funding initiatives directed at facilitating academic networks. However, there is little evidence about whether collaboration or individual achievement are better for a rising academic (Kemp 2013) or about why people collaborate on these collective activities.

Our objective is to measure whether expectations about the perceived prospects for the quality of one's research environment can affect contributions of researchers to an academic network. Specifically, we surveyed researchers on their "intrinsic" expectations. In so doing, we randomly provoked optimistic vs. pessimistic expectations with a small nudge in our email invitation to join our network. We provide results on the nudge effectiveness, and also on researchers' expectations about their future research environment, and their motivations to contribute to our network.

\section{Empirical strategy}

2.1 Modelling framework, experimental design, and hypotheses

We frame the contribution to a research network as a public good game, where the net benefits from contribution to the public (the REECAP network) and the private (other research activities) goods are uncertain, noting that the research environment quality is likely to be uncertain

\footnotetext{
1

Marianne Lefebvre (contact author: marianne.lefebvre@univ-angers.fr) is at the Université d'Angers, France. Jens Rommel is at the Swedish University of Agricultural Sciences, Upsalla, Sweden. Jesus Barreiro-Hurlé is with the European Commission Joint Research Centre, Seville, Spain. The authors thank the REECAP members for their responses to the survey and involvement in the network. The views expressed are purely those of the authors and may not in any circumstances be regarded as stating an official position of the European Commission.
} 
during to the Covid pandemic. The experimental public good literature has explored the role of uncertainty and expectations about other players' behaviour (strategic uncertainty), and environmental uncertainty when the net benefits from contribution to the public good are unknown (Gangadharan and Nemes 2009). Contributions to the public good depend on the perception of the costs and benefits of participation, relative to the costs and benefits of developing other non-collective activities.

Nudges are subtle behavioral interventions based on the modification of the choice architecture, i.e., the context in which people make decisions (Thaler 2020). The goal of a nudge is to alter people's behaviour in a predictable way, but without limiting options or significantly changing their economic incentives. To count as a nudge, the intervention must be easy and cheap to avoid (Thaler and Sunstein 2009, 6). Social nudges or "social benefits nudges" (Boven 2009) use messages that "induce people to shift from I-frame to we-frame in social dilemmas," thereby increasing pro-social, group-oriented behaviour (Nagatsu 2015). The nudge we use in this experiment manipulates the perception of the future research environment, likely to impact the costs of research activities and therefore the net benefits from private vs. network activities. In so doing, we aim to generate more or less contribution to the public good (the modelling framework is presented below).

Inspired by Etner et al. (2009), we developed two treatments manipulating the outlook on the future research environment as either optimistic or pessimistic. As the experiment was implemented during the COVID-19 pandemic ${ }^{2}$ we took advantage of the uncertainty concerning the postpandemic research environment to present two alternative states of the world (The COVID-19 Scientist Survey ${ }^{3}$ ). Note that, in a highly uncertain environment and with heterogeneous impacts of the pandemic on individuals, both statements may be true. The pandemic may have negative effects (e.g., Woolston 2020), but it also creates new opportunities for research and exchange (e.g., Salguero-Gómez 2020). Thus, our treatments should not be considered as deceptive, but rather as two framings of possible futures in a highly uncertain world that do not contradict each other. ${ }^{4}$ Specifically, in an invitation to contribute to the REECAP research network, potential participants received either a positive (T1), a negative (T2), or no (CONTROL) message. The statements read as follows:

T1: Under current circumstances, we are already seeing EU researchers being very active to keep up their work to assure we are ready for better policy making post COVID. We believe REECAP activities can contribute to this.

T2: Under current circumstances, we are already seeing a decline in research capacity and activity in the areas not directly related to COVID. We believe REECAP activities can help to avoid this.

We tested the following hypotheses:

H1: Providing information on a good future research environment will reduce contributions to the network, while providing information on future a poorer research environment quality will increase contribution.

We assume a better research environment will reduce the costs of doing research in general (more opportunities in general, such as more funding available for research and therefore less effort to get research grants). As a result, contributions to the network are more likely in the negative treatment (T2) than in the control treatment since the difference between the net benefits of contributing to the network vs. other private activities is more likely to be perceived as positive. The opposite is true in T1 where positive expectations with regard to the future research environment quality could make respondents perceive the difference between the net benefits of contributing to the network vs. other private activities more likely to be negative, and therefore encourage them to contribute less.

H2: Providing information on future research environment quality will neutralize the impact of individual expectations and optimism/pessimism on the contribution to the research network. The individual measure of optimism will therefore explain individual contribution only in the control group where no information is provided.

Our second hypothesis relies on the expectation that a change in the decision framework (induced by the treatment), can neutralize individual expectations with regard to the net benefits of contributing to the public good (compared to the net benefits of private activities).

$2 \quad$ The first email was sent on the 7th of April.

$3 \quad$ https://sciencehub-covid19.info/covid-19-scientist-survey/

$4 \quad$ For a discussion on the use of deception and experimental ethics in Agricultural and Resource Economics see Cason and Wu (2019) and Colson et al. (2016). In our experiment, we implemented an ex-ante risk assessment, ex-post consent, and offered participants various debriefing options. 
Invited participants can either ignore the invitation, respond that they are not interested in contributing, respond that they are interested in contributing to the network, or respond that they are interested to contribute and lead one of the network's working groups. We merge the first two responses and the last two responses to achieve a binary outcome (being either willing or unwilling to contribute). Note that we have preregistered the hypotheses and experimental outcomes before data collection. ${ }^{5}$

\subsection{Data collection}

The sample included 89 researchers and practitioners interested in experimental approaches evaluating EU agricultural policy at the regional and national levels. These people had already signalled their interest in the REECAP network ${ }^{6}$ by filling-in a profile online. They were aware of the network's objectives, since they could read the draft proposal to the COST call of Spring 2020.

The data were collected online using a small survey. The first aim of the survey was to organize working groups of the research network on the basis of voluntary contributions of individual members to one or more working groups. The survey included two parts. The first was sent on the 7th of April 2020, the second on the 5th of May 2020. As an introduction, recipients were told that, given that the opportunity to obtain funding was postponed, the network board had decided to launch the working groups without waiting for funding, to keep the network active. No deception was involved, consent on the use of data was obtained in the second survey wave, and extensive debriefing options were offered. ${ }^{7}$

The first message had three versions, which - among other things - included the different statements described above. In total, 89 people received the invitation whom we randomly allocated to one of the three treatments described above. The second part was announced together with a debriefing message indicating that the first message included a nudge. The message inviting participants to complete the second part of the survey was sent to the full sample, with differentiated messages depending on participants' responses to the first message. The second part of the survey allowed us to collect individual data on optimism attitudes obtained from the revised life orientation test (Scheier et al. 1994), as well as self-reported expectations concerning the research environment quality in the future. The future dimension was not specified in terms of timespan or with explicit mention as being post-COVID-19. However, as the data collection took place at the height of the pandemic, we can assume the future as post-COVID-19. We also collected feedback on participants' beliefs about the effectiveness of the treatment and on their willingness to contribute to the network. In addition, we obtained consent to share the data.

61 people completed the first part of the survey and 48 the second part. 36 completed both. One person did not consent to the use of the responses. The final sample size is 88 for the willingness to contribute variable and 47 for the explanatory variables collected in the second part.

\section{Results}

Table 1 shows positive outcomes by treatments. Respondents showed the greatest willingness to contribute in the pessimistic treatment, followed by the optimistic and control conditions.

Table 1: Willingness to contribute (positive outcome) by treatments

\begin{tabular}{llll}
\hline & $\begin{array}{l}\text { T1 (optimistic) } \\
\mathrm{n}=29\end{array}$ & $\begin{array}{l}\text { T2 (pessimistic) } \\
\mathrm{n}=30\end{array}$ & $\begin{array}{c}\text { Control } \\
\mathrm{n}=29\end{array}$ \\
\hline $\begin{array}{l}\text { Absolute number of } \\
\text { positive outcomes } \\
\begin{array}{l}\text { Percentage of } \\
\text { positive outcomes }\end{array}\end{array}$ & 14 & 11 \\
\hline
\end{tabular}

5 The pre-registration is available at https://aspredicted.org/blind.php? $\mathrm{x}=\mathrm{fg} 2 \mathrm{q} 6 \mathrm{n}$.

$6 \quad$ The Research Network on Economic Experiments for CAP evaluation (REECAP) is an EU-wide informal consortium open to those who wish to promote behavioural analysis and economic experimental designs for the ex-ante and ex-post evaluation of the Common Agricultural Policy. reecap.org

The full text of the survey is available in the on-line Electronic Supplementary Material 
Pairwise testing shows that T2 is marginally significantly $(p<0.1)$ different from the control condition (one-sided two-sample test of proportions, $z=1.441, p=0.075)$. In spite of rather large differences, the other two pairwise tests are not statistically significant, but note that the sample size is small, making both a type I and a type II errors more likely.

To further explore the data, we ran probit models. We found again that T2 is marginally statistically significant $(p<0.1)^{8}$ but no gender or country effects are evident (model 1 in Table 2). Interacting treatment variables with variables capturing intrinsic expectations about future research environment quality (model 2) and general optimism attitude (model 3), does not show support for hypothesis 2 and the treatment effect obtained in model 1 cancels out.

We conclude that the change in the decision framework (induced by the treatment) is not sufficient to neutralize individual expectations about the net benefits of contributing to the network (compared to the net benefits of private activities). Moreover, the variables capturing intrinsic expectations about the future research environment quality (FRQE) and general optimism attitude (LOT) do not explain individual expectations about net benefits of contributing to the network.

Overall, we cannot find support for the two formulated hypotheses, although the directions of the effects are in line with our expectations, and the effect sizes appear sizeable. In the post-experimental survey, we included an open question on the perceived effectiveness of the nudge. The responses were varied. While some argued that a small message in an email would not affect their decisions, others expected small effects. For further analysis and an investigation of interaction effects, a larger sample size would be needed.

Table 2: Probit model explaining the willingness to contribute

\begin{tabular}{|c|c|c|c|}
\hline \multirow{2}{*}{\multicolumn{4}{|c|}{ VARIABLES }} \\
\hline & & & \\
\hline T1 (optimistic) & $\begin{array}{c}0.66 \\
(0.48)\end{array}$ & $\begin{array}{l}-2.23 \\
(2.87)\end{array}$ & $\begin{array}{c}2.90 \\
(2.85)\end{array}$ \\
\hline T2 (pessimistic) & $\begin{array}{l}0.86^{*} \\
(0.47)\end{array}$ & $\begin{array}{l}-1.16 \\
(1.83)\end{array}$ & $\begin{array}{l}-5.68 \\
(4.35)\end{array}$ \\
\hline Female & $\begin{array}{c}0.50 \\
(0.39)\end{array}$ & & \\
\hline ITC & $\begin{array}{c}0.37 \\
(0.58)\end{array}$ & & \\
\hline FRQE & & $\begin{array}{l}-0.38 \\
(0.40)\end{array}$ & \\
\hline T1xFRQE & & $\begin{array}{c}0.82 \\
(0.77)\end{array}$ & \\
\hline T2xFRQE & & $\begin{array}{c}0.59 \\
(0.52)\end{array}$ & \\
\hline LOTscore & & & $\begin{array}{c}0.083 \\
(0.089)\end{array}$ \\
\hline T1xLOTscore & & & $\begin{array}{l}-0.13 \\
(0.16)\end{array}$ \\
\hline T2xLOTscore & & & $\begin{array}{c}0.39 \\
(0.26)\end{array}$ \\
\hline Constant & $\begin{array}{c}-0.78^{* *} \\
(0.39)\end{array}$ & $\begin{array}{c}0.74 \\
(1.34)\end{array}$ & $\begin{array}{l}-1.90 \\
(1.57)\end{array}$ \\
\hline Observations & 47 & 47 & 47 \\
\hline
\end{tabular}

$8 \quad$ Note that the regression table below reports significance levels for a two-sided test. Applying a one-sided test (as in the raw comparison) would lead to a p-value < 0.05. But also note that the sample differs, because it only includes those who have answered to the second questionnaire. 
Note: ITC means that the respondent works in a less research-intensive country (entitled Inclusiveness Target Country in the COST EU program). FRQE measures on a Likert scale from 1 (totally pessimistic) to 5 (totally optimistic) individual expectations with regard to the future quality of the research environment (access to funding and equipment, possibility to recruit a research assistant, international collaborations, freedom, pressure to publish, chance to obtain a tenured position, etc.). $11 \%$ were totally or rather pessimistic, $25 \%$ were neutral, $55 \%$ rather optimistic, and $9 \%$ totally optimistic. LOT score measures general optimism attitudes according to the revised life orientation test (Scheier et al. 1994)

\section{Discussion and conclusion}

We studied voluntary participation of people with an expressed interest in a research network of experimental agricultural economists. Despite sizeable effects in the theoretically expected direction, we did not find statistically significant effects of pessimistic or optimistic messaging. A major limitation was the small sample size, which was predetermined by the 89 people who showed interested in being part of the network. The large estimated treatment effects indicate a potential to repeat the investigation with a larger sample, even if the scalability of nudge results has been challenged recently (DellaVigna and Linos 2020). Given the strong commitment of some people to the network, other drivers may play a greater role than the relatively small effect of message framing, which could indicate that the nudge may work better in environments where the decision is more spontaneous and open. Here, we could not study heterogeneous treatment effects in greater depth, since to do so requires a more statistically powerful experiment.

\section{References}

Ansmann, L., Flickinger, T. E., Barello, S., Kunneman, M., Mantwill, S., Quilligan, S., ... \& Aelbrecht, K. (2014). Career development for early career academics: Benefits of networking and the role of professional societies. Patient Education and Counseling, 97(1), $132-134$.

Bovens, L. (2009). The ethics of nudge. In Preference Change: Approaches from Philosophy Economics and Psychology, chapter 10, eds. T. Grüne-Yanoff and S. O. Hansson, 207-219. Springer, New York.

Cason, T. N., \& Wu, S. Y. (2019). Subject pools and deception in agricultural and resource economics experiments. Environmental and Resource Economics, 73(3), 743-758.

Colson, G., Corrigan, J. R., Grebitus, C., Loureiro, M. L., \& Rousu, M. C. (2016). Which deceptive practices, if any, should be allowed in experimental economics research? Results from surveys of applied experimental economists and students. American Journal of Agricultural Economics, 98(2), 610-621.

DellaVigna, S., \& Linos, E. (2020). RCTs to Scale: Comprehensive Evidence from Two Nudge Units. Working Paper, UC Berkeley.

Etner, J., Jeleva, M., \& Jouvet, P. A. (2009). Pessimism or optimism: a justification to voluntary contributions toward environmental quality. Australian Economic Papers, 48(4), 308-319.

Kemp, A. T. (2013) Collaboration vs. Individualism: What Is Better for the Rising Academic? The Qualitative Report, 18(100), 1-8

Nagatsu, M. (2015). Social nudges: their mechanisms and justification. Review of Philosophy and Psychology, 6(3), 481-494.

Salguero-Gómez, R. (2020). How I ran a virtual research retreat during a pandemic. Nature, 584(7820), 316-316.

Scheier, M. F., Carver, C. S., \& Bridges, M. W. (1994). Distinguishing optimism from neuroticism (and trait anxiety, self-mastery, and selfesteem): a reevaluation of the Life Orientation Test. Journal of Personality and Social Psychology, 67(6), 1063 -1078.

Thaler, R. H., \& Sunstein, C. R. (2009). Nudge: Improving decisions about health, wealth, and happiness. Penguin.

Woolston, C. (2020). Pandemic darkens postdocs' work and career hopes. Nature, 585(7824), 309-312. 